\title{
Suppression during binocular fusion of complex targets'
}

ROBERT FOX AND CURTIS MEINTYRE VANDERBILT UNIVERSITY

Forced-choice form recognition thresholds were obtained for both eyes concurrently during fusion of targets varying in contour density. For targets with many contours, decrements in recognition were found which were consistent with the assumption that suppression during fusion occurs when the targets have complex configurations. The results support a modified form of the suppression theory.

When the eyes fixate a common object, the monocular signals combine to form a single binocular percept. This phenomenon of binocular combination or fusion is well known, and considerable data has accrued concerning the stimulus conditions which govern its occurrence. Less is known about the mechanism that underlies the combining operation. At present, two alternative hypotheses can be considered. The fusion theory asserts that the binocular percept is the product of facilitatory interaction between the monocular signals. According to the suppression theory, the single percept results from the inhibition of one monocular signal by its partner.

The logic of an indirect test of the suppression theory by means of a test-probe method has been described previously (Fox \& Check, 1966a). Application of that method to binocular rivalry has demonstrated that suppression acts to inhibit test stimuli. If a similar suppression process operates during fusion, similar inhibitory effects should be found.

In the previous experiment (Fox \& Check, 1966a) no evidence for inhibition during fusion was obtained -a result which cannot be accommodated by current statements of the suppression theory (e.g., Asher, 1953). However, such formulations employ only a few rather strong assumptions and may, in fact, be unnecessarily restrictive.

To provide a more generous evaluation of the viability of the concept of suppression during fusion, a modification of the theory is proposed and tested in the present experiment. The theoretical modification is the assumption that suppression is contingent upon the complexity (defined in terms of contour density) of the fused targets; 1.e., that suppression occurs only when the signal strength in the monocular channels exceeds some level. To evaluate this hypothesis, we obtained forced-choice recognition thresholds for letter forms viewed against fusion targets which varied in contour complexity. The letter recognition task is one known to be sensitive to the suppression induced by binocular rivalry (Fox \& Check, 1966b). Method

Subjects. Three male Ss with normal vision and ex- perience in psychophysical observation were employed. DC and SS were right-eye dominant while RC was left-eye dominant, as assessed by the Miles funnel test.

Apparatus. Details of the equipment and much of the procedure have been described previously (Fox \& Check, 1966b). A Wheatstone stereoscope provided 70 left and right eye fields located $71 \mathrm{~cm}$ from $S$ and viewed through $2 \mathrm{~mm}$ artificial pupils. A tachistoscope lighting and logic system (Scientific Prototype Corp., Model H) was used to present the test stimuli upon these fields.

The major variable was the configuration of the fusion targets. In Fig. 1 the two classes of fusion targets are illustrated. Both the simple and complex targets consisted of $3^{\circ} 30^{\prime}$ squares seen against transilluminated white grounds with a constant luminance of $5 \mathrm{ft}-\mathrm{L}$. The extent of the contour-free area of the complex square was $39^{\prime}$.

The test stimuli consisted of three $16^{\prime}$ letters (A, $T$, and $U$ ) which were presented in the blank center area of the complex target and at a corresponding place in the simple target.

\section{Design and Procedure}

Two steps were involved in the general design. First, stable recognition thresholds in the range of 60-70\% correct recognition for each eye of each $S$ were determined under conditions of fusion assumed not to generate suppression. Second, the effect of combinations of the simple and complex fusion targets upon the recognition thresholds was determined. Figure 1 illustrates the four target combination conditions and the theoretically relevant comparisons. Binocular

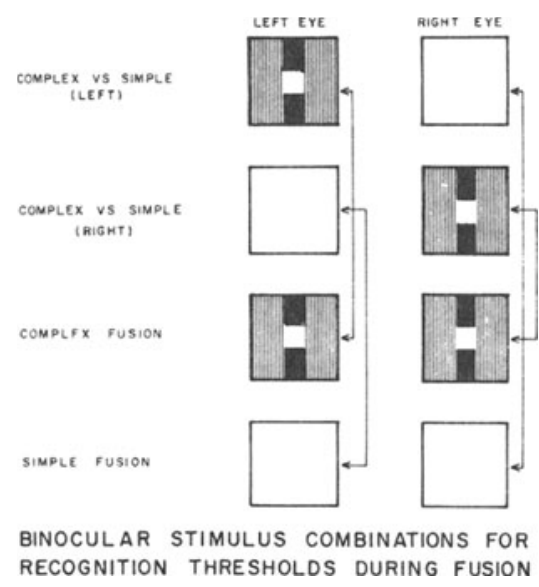

Fig. 1. Configuration of the simple and complex fusion targets and the theoretically relevant comparisons. 
combination of the complex targets (Condition $\mathrm{C}-\mathrm{C}$ ) should generate interocular suppression. A control for this condition is provided by the case where an eye is stimulated by a complex target that is paired with a simple target in the other eye (i.e., S-C and $\mathrm{C}-\mathrm{S})$. When simple targets are combined binocularly (S-S), by hypothesis suppression should not occur. This condition provides a control for the possibility that the eye receiving the simple target is suppressed by the presence of a complex target in the other eye. There is no theoretical reason for comparing the S-S and $\mathrm{C}-\mathrm{C}$ conditions.

To determine the baseline recognition thresholds, each $S$ received about 200 practice trials both with the simple targets paired with a contralateral blank field and with the simple targets combined binocularly. The luminance and duration (range, 40-60 msec) of the test flashes were adjusted so that the thresholds for each S reached the 60-70\% correct level. During this period it was also established that the threshold for an eye stimulated by a simple target was not changed by the presence or absence of a fused simple target in the other eye (i.e., suppression was not operative between the simple squares).

After the practice period the four combinations of fusion target conditions were administered following a balanced Latin square design. Under each condition and for each S a total of 144 left eye and 144 right eye trials were given (96 trials in a single session, 12 left eye and 12 right eye trials for each condition). The schedule of presentation between eyes and among letters was randomized with the restriction of equal occurrence.

On each trial the fusion squares were carefully aligned to prevent disparity. Ss initiated the test flash after they had obtained clear fusion and fixated the center of the fusion squares. White noise masked apparatus sounds between trials.

\section{Results}

Since no significant difference was found between the separate eyes of $\mathrm{RC}$ and $\mathrm{DC}$, the data was combined for both eyes of each $\mathrm{S}$. A difference between eyes $(F=10.48, d f=1 / 33, p<.01)$ was found in the case of SS, but this can be attributed to a difference in the initial baseline of recognition established for the separate eyes; a test with eyes combined was performed on the data of this $S$ also. For all Ss the difference between conditions was significant: for $\mathrm{RC}, \mathrm{F}=11.93, \mathrm{df}=3 / 33, \mathrm{p}<.01$; for $\mathrm{DC}, \mathrm{F}=17.77$, df $=3 / 33, p<.01 ;$ for SS, $F=8.29, d f=3 / 33, p<.01$. The results combined over eyes are given for each $\mathrm{S}$ in Fig. 2.

The Newman-Keuls multiple comparison method was applied to the condition means for each $S$ with $p=.05$. No significant difference was found in the $\mathrm{S}-\mathrm{S} / \mathrm{C}-\mathrm{C}$

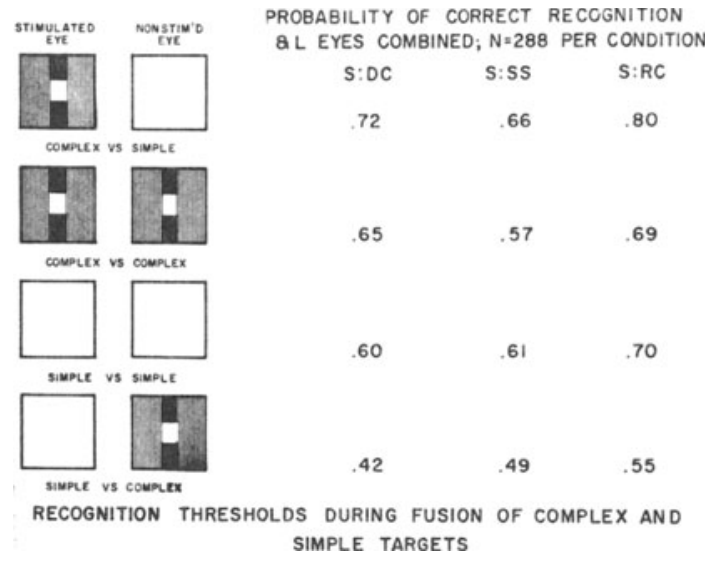

Fig. 2. Mean recognition scores for each $\mathrm{S}$, combined over eyes, for each condition.

comparison for any $S$. Significant differences were found for each $\mathrm{S}$ on the $\mathrm{S}-\mathrm{S} / \mathrm{S}-\mathrm{C}, \mathrm{S}-\mathrm{C} / \mathrm{C}-\mathrm{S}, \mathrm{S}-\mathrm{C} / \mathrm{C}-\mathrm{C}$, and $\mathrm{S}-\mathrm{S} / \mathrm{C}-\mathrm{S}$ comparisons. The $\mathrm{C}-\mathrm{S} / \mathrm{C}-\mathrm{C}$ comparisons were significant for SS and $\mathrm{RC}$, but not for $\mathrm{DC}$; however, the difference for this $S$ was significant at the $\mathrm{p}=.10$ level.

\section{Discussion}

The results are consistent with the assumption that stimulation of an eye by a complex target initiates a contralateral inhibitory suppression process. Thus, the threshold difference between the $\mathrm{C}-\mathrm{S}$ and $\mathrm{C}-\mathrm{C}$ conditions is due to competitive interocular suppression produced by the presence of a complex target in each eye. Similarly, the difference between the S-S and the $\mathrm{S}-\mathrm{C}$ conditions is due to suppression of the simple target by the contralateral complex target.

A number of alternative interpretations of these data have been considered, but we have found none more compelling than the suppression hypothesis. Hence, we are forced to conclude that suppression is not a negligible factor in the binocular combination or fusion of multicontoured targets. It should be noted that previous research on binocular interaction (e.g., summation) does not bear upon the evaluation of the present data, since previous experiments have employed rather simple stimulus conditions that would not be expected to induce suppression.

\section{References}

Asher, H. Suppression theory of binocular vision. Brit. J. Ophthal., $1953,37,37-49$.

Fox, R., \& Check, R. Binocular fusion: A test of the suppression theory. Percept. \& Psychophys., 1966a, 1, 331-334.

Fox, R., \& Check, R. Forced-choice form recognition during binocular rivalry. Psychon. Sci., 1966b, 6 (10), 471-472.

\section{Note}

1. This research was supported by grant $M H 08934$ from the U. S. Public Health Service. 